\title{
Determination of an Ideal Stimulation Site of the Medial Antebrachial Cutaneous Nerve Using Ultrasound and Investigation of the Efficiency
}

\author{
Chang Hoon Oh, MD, Nam Su Park, MD, Jae Min Kim, MD, PhD, Min Wook Kim, MD, PhD \\ Department of Rehabilitation Medicine, Incheon St. Mary's Hospital, \\ The Catholic University of Korea College of Medicine, Seoul, Korea
}

\begin{abstract}
Objective To determine an ideal stimulation site of the medial antebrachial cutaneous nerve (MACN) using ultrasound measurement and to compare the efficiency of the new stimulation site with the conventional stimulation site on the nerve conduction study.

Methods Both arms of 15 healthy participants were measured using ultrasound. The MACN was identified in the transverse view at each $0,2,4,6$, and $8 \mathrm{~cm}$ proximal sites from the medial epicondyle, and the distances to the median nerve and to the skin from the MACN were measured. The ideal stimulation site should be located at the level which can give the shortest distance from the skin and the longest distance from the median nerve in terms of volume conduction. To confirm the efficiency of the ideal site, we measured the amplitude of the MACN conduction study at the ideal site against one at the $4 \mathrm{~cm}$ proximal to the medial epicondyle (conventional site).

Results The ultrasound showed the ideal stimulation site for the MACN could be the elbow crease line. However, the nerve conduction study revealed that the amplitudes of the MACN were significantly larger at the $4 \mathrm{~cm}$ proximal to the medial epicondyle compared with ones at the ideal site.

Conclusion The ideal stimulation site based on the ultrasound did not permit better stimulation site for the nerve conduction study of the MACN compared with the conventional site. Careful adjustment of the stimulation site on the basis of this study would contribute to an accurate conduction study of the MACN.
\end{abstract}

Keywords Medial antebrachial cutaneous nerve, Ultrasonography, Neural conduction

\section{INTRODUCTION}

Received May 13, 2014; Accepted August 1, 2014

Corresponding author: Min Wook Kim

Department of Rehabilitation Medicine, The Catholic University of Korea College of Medicine, 222 Banpo-daero, Seocho-gu, Seoul 137-701, Korea Tel: +82-32-280-5858, Fax: +82-32-280-5040, E-mail: minukkim@nate. com

(c) This is an open-access article distributed under the terms of the Creative Commons Attribution Non-Commercial License (http://creativecommons. org/licenses/by-nc/3.0) which permits unrestricted noncommercial use, distribution, and reproduction in any medium, provided the original work is properly cited.

Copyright $\odot 2014$ by Korean Academy of Rehabilitation Medicine
The medial antebrachial cutaneous nerve (MACN) originated from the medial cord and was derived from segments C8 and T1 [1-5]. At the arm, the MACN coursed distally until it pierces the deep fascia $10 \mathrm{~cm}$ above the medial epicondyle and divided into anterior and posterior branches providing the sensory supply of the medial aspect of the forearm [2-4]. Sensory-nerve conduction study of the MACN has been commonly used for the evaluation of brachial plexopathy, neurogenic thoracic 
outlet syndrome, or nerve injury of the upper extremity [2,3,6-10]. Antidromic sensory conduction study was the standard method, where the stimulation was given at or above the elbow, and the sensory nerve action potential (SNAP) was picked up over the forearm [10]. Various methods were suggested about the stimulation sites of MACN in several articles and literature, from the medial elbow to the $5 \mathrm{~cm}$ proximal of the medial epicondyle [2,6,10-13]. The most commonly used method was published by Ma et al. [14]. The stimulation site was recommended that it be located $4 \mathrm{~cm}$ proximal to the medial epicondyle in the groove overlying the neurovascular bundle between anterior and posterior muscle compartments of the arm $[14,15]$.

The MACN conduction study sometimes required more careful technique compared with other nerves because it was quite easy to co-activate the nearby median nerve with volume-conducted potentials, overwhelming the small sensory response $[14,15]$. However, there has never been a proper investigation into the ideal stimulation site of the MACN or the comparison between the stimulation sites.

We hypothesized that the ideal stimulation site of the MACN may be the point that was sufficiently satisfied nearby the skin and far from the median nerve. The purposes of this study were to determine the ideal stimulation site of the MACN using ultrasound measurement and to compare the efficiency of the new stimulation site with that of the conventional stimulation site on the nerve conduction study.

\section{MATERIALS AND METHODS}

\section{Subjects}

This study was approved by the Institutional Review Board of the Incheon St. Mary's Hospital. All participants provided informed consent in accordance with the guidelines of the ethics committee.

Fifteen healthy participants were recruited internally through advertisements. Presence of the following conditions excluded participation from the study: history of trauma of the arm, previous surgery to the cervical spine, shoulder or upper extremity, cervical radiculopathy, brachial plexopathy, thoracic outlet syndrome, peripheral neuropathy including peripheral nerve entrapment, polyneuropathy, and dermatologic lesions that might interrupt the examination of the ultrasound or the nerve conduction study.

\section{Methods}

\section{Ultrasound measurement}

Ultrasound scans of all subjects were performed using a Philips HD11XE ultrasound system with a 5-12 MHz linear transducer (Philips Medical System, Cleveland, OH, USA). Thirty arms from 15 healthy participants were examined. One physiatrist, who had experience with peripheral nerve ultrasound, conducted the examination. In supine position, the arm was $45^{\circ}$ abducted and externally rotated with full elbow extension for the duration of the ultrasound scan, which was approximately 15 minutes at each side. The MACN was identified in a cross-sectional view at the mid-arm level (Fig. 1). Subsequently, the nerve was tracked in a distal direction until its division (anterior and posterior branches). The distance from the division point to the medial epicondyle was measured. The MACN or the anterior branch of the MACN was scanned in the short axis view at each 0,2 , 4,6 , and $8 \mathrm{~cm}$ proximal sites from the elbow crease line, and the distances to the median nerve and to the skin from the MACN were measured (Fig. 2). The ultrasound

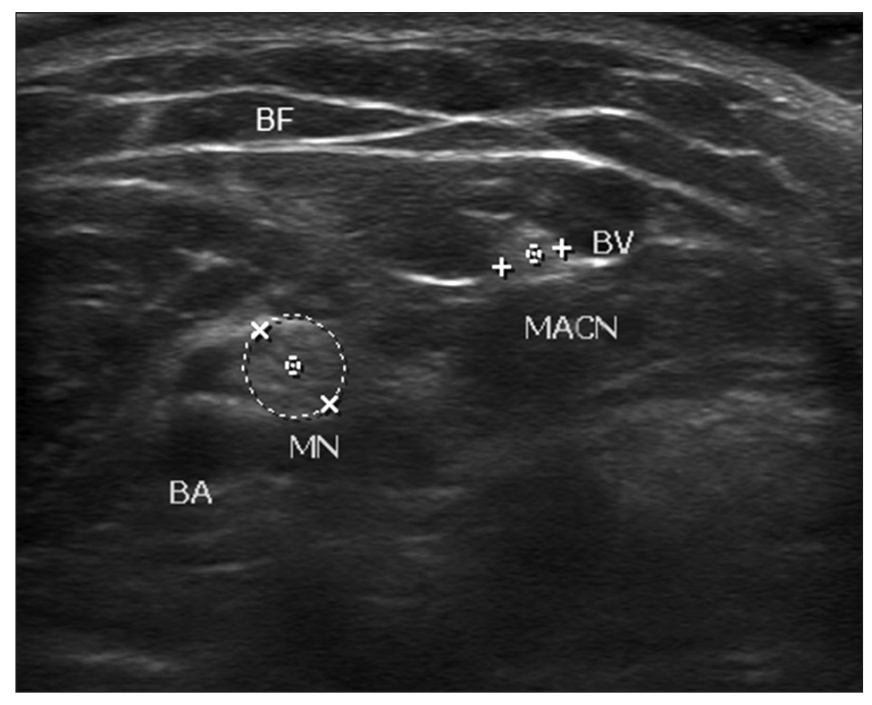

Fig. 1. Ultrasound illustration of the MACN and the adjacent anatomy at $6 \mathrm{~cm}$ proximal to the medial epicondyle in a 33-year-old man. Left side of the image is radial (lateral) side of the arm. MACN, medial antebrachial cutaneous nerve; $\mathrm{MN}$, median nerve; $\mathrm{BA}$, brachial artery; BV, basilic vein; $\mathrm{BF}$, brachial fascia. 

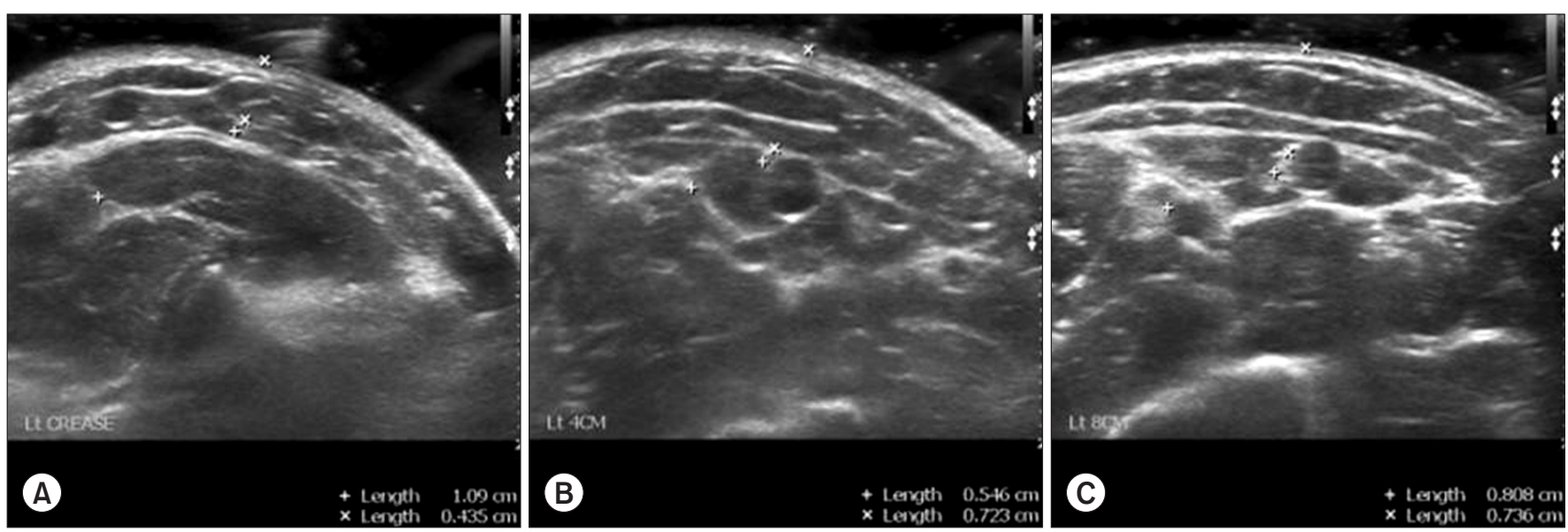

Fig. 2. Ultrasound image illustrated the $\mathrm{MACN}$ at 0,4 , and $8 \mathrm{~cm}$ proximal to the medial epicondyle in a 28-year-old healthy woman. Cross sectional view at the elbow crease line (A), $4 \mathrm{~cm}(\mathrm{~B})$, and $8 \mathrm{~cm}$ (C) proximal site from the medial epicondyle. The distance between to the median nerve (+-+) and to the skin (x-x) from the MACN were measured. To avoid pressure to the skin, we applied the ultrasound probe lightly over the skin with enough transducer gel. MACN, medial antebrachial cutaneous nerve.

transducer was applied lightly over the skin with enough transducer gel to avoid pressure to the skin. Finally, the MACN was kept in the center of the field-of-view of the ultrasound image at the elbow crease line, and then we marked this point and measured the surface distance between the MACN and the medial epicondyle. After measuring these parameters of an arm, we determined an ideal stimulation site of the MACN at each arm on the basis of our hypothesis.

\section{MACN conduction study}

After ultrasound measurement, sensory nerve conduction studies of the MACN were conducted. The skin temperature measured at the forearm was maintained at $32^{\circ} \mathrm{C}$ or above throughout the examination. We compared the MACN conduction studies of the two stimulation sitesan ideal site according to our ultrasound findings and the conventional stimulation site on $4 \mathrm{~cm}$ proximal to the medial epicondyle.

We used the two-step method established by Higashihara et al. [10] for determining the best recording position for the standard antidromic nerve conduction study. For the two-step examination, we first performed an orthodromic MACN conduction study only for the purpose of the determination of the optimal active electrode position, by reversing the stimulating and recording electrodes of the antidromic method. We searched for the optimal stimulation point over the forearm while monitoring the orthodromic SNAP so that the SNAP amplitude would become as large as possible with a very weak stimulation (usually $10 \mathrm{~mA}$ with $0.05 \mathrm{~ms}$ duration). We then reversed the electrodes and performed the antidromic conduction study, recording right over the minimal threshold point as determined above.

The SNAP was recorded $12 \mathrm{~cm}$ distal to the stimulation site equally. The SNAP parameters were recorded at the maximal current that the SNAP amplitude would become as large as possible without volume-conducted potentials. The latency was measured to negative peak of the SNAP, and the amplitude was measured from peak to peak.

\section{Statistical analysis}

Mean, standard deviation (SD), and range of the ultrasound parameters were calculated and expressed as mean $\pm S D$ (range). Statistical differences of each segment in the data of ultrasound were analyzed using repeated measures ANOVA. The nerve conduction data were tested for a normal distribution using the Shapiro-Wilk test and the Kolmogorov-Smirnov test. The paired-samples $\mathrm{t}$-test was used to compare parametric data with a normal distribution, and the Wilcoxon signed-rank test was used to compare nonparametric data with a non-normal distribution. A p-value of 0.05 or less was considered statistically significant. Statistic analyses were performed using SPSS software ver. 20.0 (IBM SPSS Inc., Armonk, 
NY, USA).

\section{RESULTS}

Fifteen healthy participants were nine men and six women with a mean age of $31.3 \pm 4.3$ years (range, $25-42$ years). The mean body mass index was $22.8 \pm 3.0 \mathrm{~kg} / \mathrm{m}^{2}$ (range, $17.2-27.7 \mathrm{~kg} / \mathrm{m}^{2}$ ). The mean distance between the median nerve and the MACN was $1.61 \pm 0.60 \mathrm{~cm}$ at $0 \mathrm{~cm}$, $1.04 \pm 0.53 \mathrm{~cm}$ at $2 \mathrm{~cm}, 0.85 \pm 0.40 \mathrm{~cm}$ at $4 \mathrm{~cm}, 0.68 \pm 0.27 \mathrm{~cm}$ at $6 \mathrm{~cm}$, and $0.62 \pm 0.27 \mathrm{~cm}$ at $8 \mathrm{~cm}$ proximal site from the elbow crease line (Fig. 3), and the mean distance from the skin to the MACN measured $0.48 \pm 0.19 \mathrm{~cm}$ at $0 \mathrm{~cm}$, $0.70 \pm 0.20 \mathrm{~cm}$ at $2 \mathrm{~cm}, 0.83 \pm 0.31 \mathrm{~cm}$ at $4 \mathrm{~cm}, 0.94 \pm 0.39 \mathrm{~cm}$ at $6 \mathrm{~cm}$, and $0.98 \pm 0.41 \mathrm{~cm}$ at $8 \mathrm{~cm}$ proximal level from the elbow crease line. The mean distance between the MACN and the medial epicondyle at the elbow crease line was $2.85 \pm 0.36 \mathrm{~cm}$ (range, $2.0-3.7 \mathrm{~cm}$ ). The average distance from the medial epicondyle to the splitting

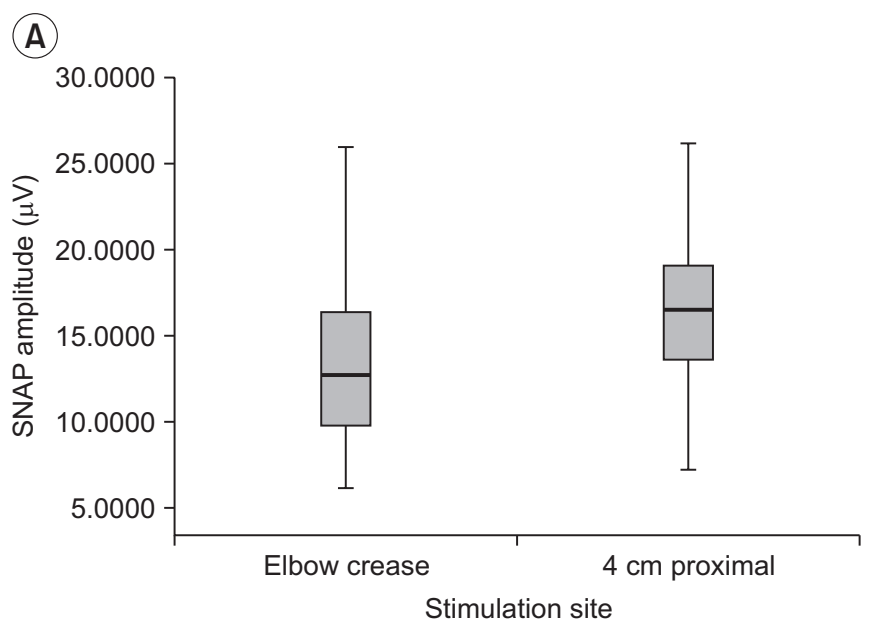

(C)

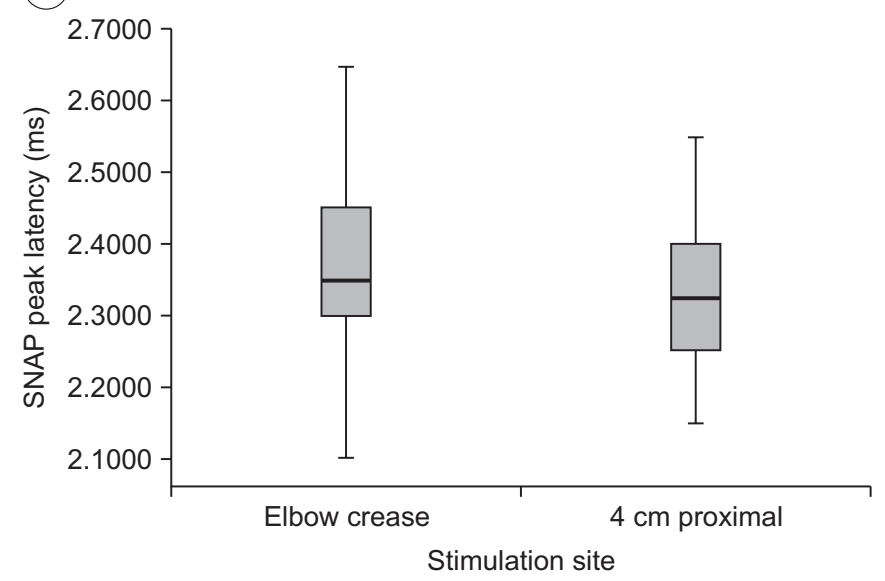

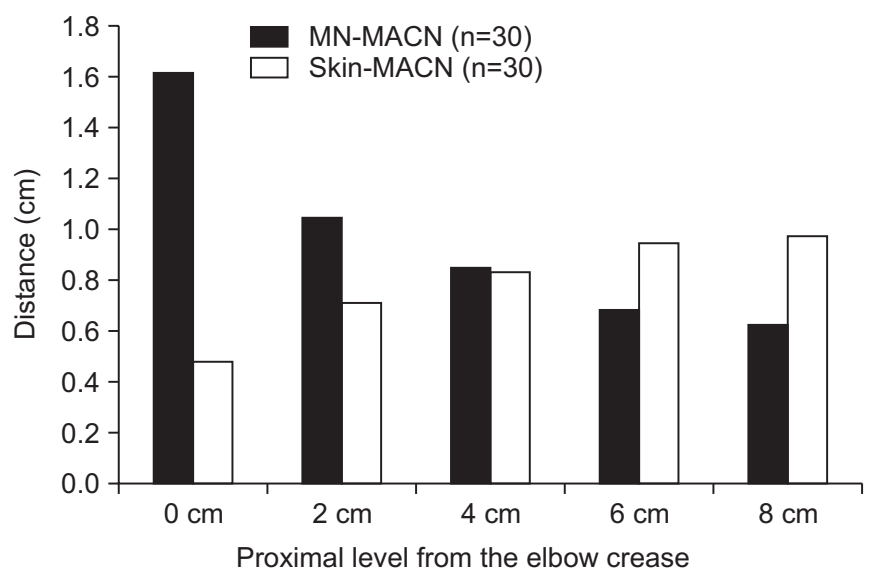

Fig. 3. Ultrasound measurement at the elbow crease level showed the shortest distance to the skin and the longest distance to the median nerve (MN) from the medial antebrachial cutaneous nerve (MACN). MN-MACN, distance between the MACN and the MN; Skin-MACN, distance between the MACN and the skin. Statistical differences of each segment in the data of ultrasound were analyzed using the repeated measures ANOVA $(\mathrm{p}<0.001)$.

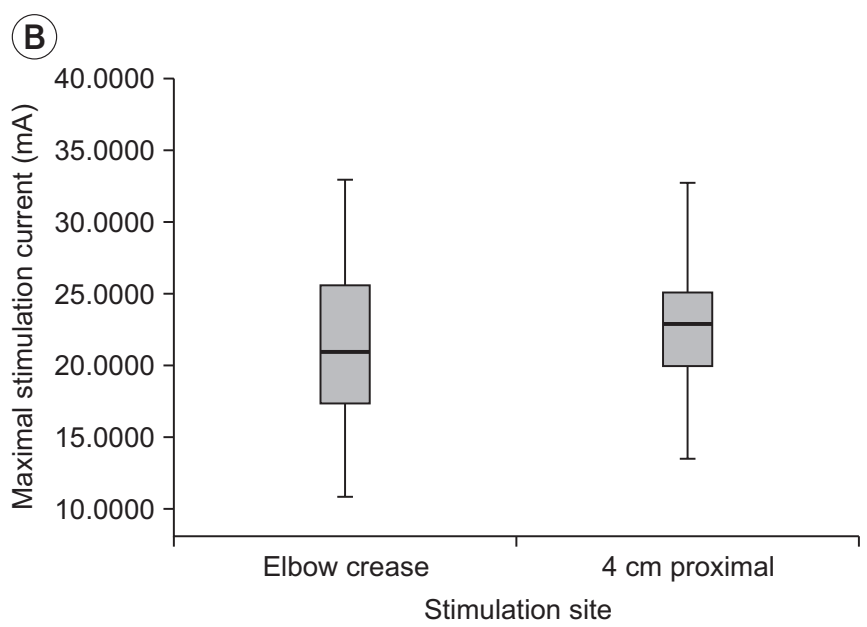

Fig. 4. Electrophysiologic results of two stimulation sites. (A) SNAP amplitude of the conventional stimulation site showed larger than that of the elbow crease stimulation site $(\mathrm{p}<0.001)$. There were no significant differences in (B) maximal stimulation current $(\mathrm{p}=0.087)$ and (C) SNAP peak latency $(\mathrm{p}=0.190)$. Elbow crease, data on the elbow crease stimulation; 4 $\mathrm{cm}$ proximal, data on the conventional stimulation (4 $\mathrm{cm}$ proximal to the medial epicondyle); SNAP, sensory nerve action potential. $\mathrm{p}$-values were calculated using the paired-samples t-test for continuous variables. 
of anterior and posterior branches of the MACN was $5.05 \pm 1.65 \mathrm{~cm}$ (range, 2.5-9.5 cm). Results from repeated measures ANOVA revealed significant difference between the distance from the skin to the MACN at each segment we measured (Greenhouse-Geisser correction, $\mathrm{p}<0.001$; Huynh-Feldt correction, $\mathrm{p}<0.001$ ). In addition, the mean distance from the median nerve to the MACN between each segment also showed significant difference (Greenhouse-Geisser correction, $\mathrm{p}<0.001$; Huynh-Feldt correction, $\mathrm{p}<0.001)$.

After the ultrasound measurement of $30 \mathrm{arms}$, the ideal site of 29 arms was determined without doubt at the elbow crease line. In only one arm, the distance between the median nerve and the MACN at the $8 \mathrm{~cm}$ proximal site was $0.06 \mathrm{~cm}$ more farther than at the elbow crease line, but the distance from skin to the MACN was also $0.69 \mathrm{~cm}$ more distant. Consequently, we chose the elbow crease line for the ideal site of the above mentioned arm, too.

There was statistically significant difference of the SNAP amplitude between the two stimulation sites (pairedsamples t-test, $\mathrm{p}<0.001)$. The SNAP amplitudes of the conventional stimulation site $(17.04 \pm 5.03 \mu \mathrm{V})$ were larger than compared with the elbow crease stimulation site $(13.38 \pm 4.75 \mu \mathrm{V})$ (Fig. 4A). However, in the viewpoint of the maximal currents, no significant difference was found ( $\mathrm{p}=0.087$; the elbow crease stimulation site, $21.83 \mathrm{~mA}$; the conventional stimulation site, $23.12 \mathrm{~mA}$ ) (Fig. 4B). The peak latencies of the MACN were also similar in two stimulation sites ( $\mathrm{p}=0.190)$ (Fig. 4C).

\section{DISCUSSION}

In our study, the ideal stimulation site was determined by two main factors-one was the site where the skin thickness was most thin and the other was the site that minimized the volume-conducted potentials. In previous study performed by Hasanzadeh et al. [16], as the distance between surface electrode and underlying sensory nerve increased, SNAP amplitude decreased, respectively. It suggested that the skin thickness was a good predictor of SNAP amplitude.

The median nerve, which was closest to the MACN in the neurovascular groove, ran distally together with MACN to the antero-medial elbow. Median nerve was most likely occurred volume-conducted potentials when the MACN was stimulated between the mid-upper arm and elbow crease. For these reasons, we measured two parameters-one was the distance between median nerve and MACN and second was the distance between the skin and MACN.

Also, co-activation of the musculocutaneous nerve could occur during MACN conduction study. Musculocutaneous nerve arose from the lateral cord of the brachial plexus. After piercing the coracobrachialis, the musculocutaneous nerve descended along the lateral aspect of the mid to lower upper arm passing obliquely between the biceps and the brachialis muscles [17]. It was possible to co-activate the musculocutaneous nerve when the stimulation site was above the mid-upper arm level. In addition, the course of the MACN at the forearm was difficult to predict because of interpersonal anatomical variation. Thus, to obtain the MACN, we have acquired parameters from the elbow crease line to the $8 \mathrm{~cm}$ proximal level above the medial epicondyle.

The ideal stimulation site of the MACN of 30 arms using ultrasound measurement were determined at the elbow crease line on the basis of comparative distances from the MACN to the median nerve and to the skin. After that, we compared the efficiency of the sensory nerve conduction studies of the MACN at both the elbow crease and conventional stimulation site. We expected that this study could clinically recommend more accurate stimulation site in sensory nerve conduction study of the MACN.

Sensory conduction technique of the MACN was first reported by Pribyl et al. [12] in 1979. He stimulated at 2-4 $\mathrm{cm}$ lateral point of the medial epicondyle and recorded 9-12 cm distally from the stimulation site. In other study performed by Reddy [11], surface stimulation was done over the medial aspect of the middle of the arm at a level where the nerve pierced the deep fascia. Seror suggested the antidromic and orthodromic conduction techniques of the MACN [2]. For the antidromic technique, the anterior branch of the MACN was stimulated $2-3 \mathrm{~cm}$ above or proximal to the medial epicondyle. The SNAP was recorded 8-12 cm distally on the antero-medial aspect of the forearm. For the orthodromic technique, the stimulation and the recording sites were reversed. Also, various methods were suggested about the stimulation sites of the MACN in several articles and literature, from the medial elbow to the $5 \mathrm{~cm}$ proximal of the medial epicondyle $[2,6,10-13]$. However, there has never been a proper 
investigation into the ideal stimulation site of the MACN or the comparison with other stimulation sites. Thus, we conducted a study that determined the ideal stimulation site of the MACN using ultrasound technique.

In ultrasound visualization of the MACN, the nerve was seen in all participants as an oval to round hyperechoic fibrillar structure below the brachial fascia. The basilic vein was the most adjacent structure to the MACN at the mid-upper arm level. When the transducer applied matching up the left side of the image with the radial (lateral) side of the arm, the MACN was located in all arms in a 6- to 12-o'clock position relative to the basilic vein at the mid-upper arm (Fig. 1), and after it divided to anterior and posterior branches, the basilic vein consistently remained interposed between the two branches. Thus, the basilic vein was worth the consideration as the landmark to search for the MACN in ultrasound technique of the upper arm. The MACN was also located medial to the brachial artery and the median nerve. At the ultrasound examination, the average distance from the medial epicondyle to the splitting of these branches was $5.05 \mathrm{~cm}$, and the mean distance between the MACN and the medial epicondyle at the elbow crease line was $2.85 \mathrm{~cm}$.

Although ultrasound visualization of the MACN was easily possible due to the constant proximity to the basilic vein and the characteristic position of the nerve relative to fascial layers, tracking the MACN distally to the elbow was more difficult, which may be due to its small size and superficial location. Thus, we used a twostep method for determining the best recording position for the standard antidromic sensory conduction study [10]. As a result, the difference of the SNAP amplitude between the two groups was statistically significance. Mean SNAP amplitude of the conventional stimulation site was larger than that of the elbow crease stimulation site. At our study's inception, we anticipated that the SNAP amplitude of the elbow crease stimulation site was meaningfully larger than that of the conventional stimulation site. Therefore, we proposed attentively some reasons for the unexpected results. First, the elbow crease line was possibly more vulnerable to volume-conducted potentials because of profuse muscle mass near under the stimulating site (e.g., flexor carpi radialis, pronator teres). Second, the recording electrode was more distally located on the elbow crease stimulation site compared with on the conventional stimulation site. The distal segment of MACN might be more slender in forearm. This locational factor might be the main reason why the mean SNAP amplitude of the elbow crease was smaller than that of $4 \mathrm{~cm}$ proximal site above the epicondyle. In future, there should be further study investigating the difference between the SNAP amplitude of sensory nerve conduction study stimulating at the proximal and the distal segment.

There were some limitations in interpreting the results of this study. To obtain correct maximal SNAP amplitudes, stimulating the skin overlying the MACN might be a troublesome procedure due to difficulty putting light pressure on the skin. Also, although the ulnar nerve and other nerves were farther from the MACN than the median nerve in the neurovascular groove at the $4 \mathrm{~cm}$ proximal to the medial epicondyle and the elbow, there was still possibility to co-conduct these nerves.

In conclusion, the ideal stimulation site based on the ultrasound did not permit better stimulation site for the sensory nerve conduction study of the MACN compared with the conventional stimulation site. For this reason, conventional stimulation site, which was located $4 \mathrm{~cm}$ proximal to the medial epicondyle, was the best stimulation point of the MACN nerve conduction study based on results of this study. However, ultrasound measurement may be a useful way to understand the MACN and the adjacent anatomy without an expensive procedure or damage to the tissue. Furthermore, careful adjustment of the stimulation site of the MACN on the basis of our study would contribute to an accurate sensory conduction study of the MACN. In addition, the applications of these findings were extended further in other nerves which were not verified stimulation sites.

\section{CONFLICT OF INTEREST}

No potential conflict of interest relevant to this article was reported.

\section{REFERENCES}

1. Thallaj A, Marhofer P, Kettner SC, Al-Majed M, AlAhaideb A, Moriggl B. High-resolution ultrasound accurately identifies the medial antebrachial cutaneous nerve at the midarm level: a clinical anatomic study. Reg Anesth Pain Med 2011;36:499-501.

2. Seror P. The medial antebrachial cutaneous nerve: an- 
tidromic and orthodromic conduction studies. Muscle Nerve 2002;26:421-3.

3. Seror P. Brachial plexus neoplastic lesions assessed by conduction study of medial antebrachial cutaneous nerve. Muscle Nerve 2001;24:1068-70.

4. Jung MJ, Byun HY, Lee CH, Moon SW, Oh MK, Shin H. Medial antebrachial cutaneous nerve injury after brachial plexus block: two case reports. Ann Rehabil Med 2013;37:913-8.

5. Sin JY, Kim DH, Bun HR, Hwang MR, Kang YK, Kwon $\mathrm{HK}$, et al. Anatomical considerations of lateral and medial antebrachial cutaneous nerves. J Korean Acad Rehabil Med 2007;31:329-32.

6. Nam YH, Kang SK. The lateral antebrachial cutaneous nerve and the medial antebrachial cutaneous nerve conduction studies in healthy Korean. J Korean Acad Rehab Med 1987;11:28-36.

7. Seror P. Medial antebrachial cutaneous nerve conduction study, a new tool to demonstrate mild lower brachial plexus lesions: a report of 16 cases. Clin Neurophysiol 2004;115:2316-22.

8. Machanic BI, Sanders RJ. Medial antebrachial cutaneous nerve measurements to diagnose neurogenic thoracic outlet syndrome. Ann Vasc Surg 2008;22:248-54.

9. Kothari MJ, Macintosh K, Heistand M, Logigian EL. Medial antebrachial cutaneous sensory studies in the evaluation of neurogenic thoracic outlet syndrome. Muscle Nerve 1998;21:647-9.
10. Higashihara M, Sonoo M, Tsuji S, Ugawa Y. Twostep technique to optimize the medial antebrachial cutaneous nerve response. Clin Neurophysiol 2010; 121:712-3.

11. Reddy MP. Conduction studies of the medial cutaneous nerve of the forearm. Arch Phys Med Rehabil 1983;64:209-11.

12. Pribyl R, You SB, Jantra P. Sensory nerve conduction velocity of the medial antebrachial cutaneous nerve. Electromyogr Clin Neurophysiol 1979;19:41-6.

13. Izzo KL, Aravabhumi S, Jafri A, Sobel E, Demopoulos JT. Medial and lateral antebrachial cutaneous nerves: standardization of technique, reliability and age effect on healthy subjects. Arch Phys Med Rehabil 1985;66:592-7.

14. Liveson JA, Ma DM. Laboratory reference for clinical neurophysiology. Philadelphia: F. A. Davis; 1992. p. 130-3.

15. Dumitru D, Amato AA, Zwarts MJ. Electrodiagnostic medicine. 2nd ed. Philadelphia: Hanley \& Belfus; 2002. p. 206-7.

16. Hasanzadeh P, Oveisgharan S, Sedighi N, Nafissi S. Effect of skin thickness on sensory nerve action potential amplitude. Clin Neurophysiol 2008;119:1824-8.

17. Tagliafico AS, Michaud J, Marchetti A, Garello I, Padua L, Martinoli C. US imaging of the musculocutaneous nerve. Skeletal Radiol 2011;40:609-16. 